\title{
MODIFICATIONS OF POST-COITAL LH SECRETION AND OESTROUS BEHAVIOUR INDUCED BY DRUGS IN OVARIECTOMIZED RATS
}

\author{
SUSANA T. BROITMAN AND ALFREDO O. DONOSO \\ Instituto de Investigaciones Cerebrales, Facultad de Ciencias Médicas, \\ Universidad Nacional de Cuyo, Mendoza, Argentina
}

(Received 24th December 1974)

\begin{abstract}
Summary. The post-coital discharge of LH was studied in ovariectomized rats primed with steroids and injected with drugs that modify oestrous behaviour. It was found that LH release was absent in receptive rats treated with $p$-chlorphenylalanine which also exhibited abnormal oestrous behaviour. Rats primed with oestrogen and progesterone and injected with DL-amphetamine showed no release of LH after mating and a decreased lordotic response.
\end{abstract}

Mating has been shown to induce an acute release of immunoreactive $\mathrm{LH}$ in female rats (Spies \& Niswender, 1971; Davidson et al., 1973; Moss \& Cooper, 1973 ) and of LH in ovariectomized rats treated with oestrogen and progesterone (Taleisnik et al., 1966). Earlier experimental evidence suggests that oestrous behaviour is controlled by cerebral monoaminergic mechanisms. Meyerson (1964) and Meyerson \& Lewander (1970) postulated that a serotonergic system inhibits oestrous behaviour; this attractive hypothesis received additional support from the observations of Zemlan et al. (1973).

The experiments reported here were conducted to explore whether a relationship exists between the LH release occurring after mating and oestrous behaviour in female rats treated with drugs known to modify monoamine activity in the brain. The drugs tested were $p$-chlorphenylalanine, a selective depletor of 5-hydroxytryptamine (Koe \& Weissman, 1966), and amphetamine, a sympathomimetic drug (Axelrod, 1970).

Normal male ( 350 to $400 \mathrm{~g}$ ) and ovariectomized (250 to $350 \mathrm{~g}$ ) Holtzman rats were kept at $22^{\circ} \mathrm{C}$ in a room under a reversed day/night rhythm (light from 20.00 to 08.00 hours). They were allowed free access to food pellets and water. Three sets of mating experiments were carried out with three groups of females: Group 1, rats with oestrous behaviour activated by oestradiol benzoate (10 $\mu \mathrm{g} / \mathrm{rat})$ and progesterone $(1 \mathrm{mg} / \mathrm{rat})$ injections given subcutaneously $48 \mathrm{hr}$ and $5 \mathrm{hr}$, respectively, before tests; Group 2, ovariectomized rats injected with $p$ chlorphenylalanine (PGPA; Regis Co.) at doses of $150 \mathrm{mg} / \mathrm{kg}$ intraperitoneally during 3 days and $350 \mathrm{mg} / \mathrm{kg}$ on the 4 th day. The rats received a single dose of oestradiol benzoate $(10 \mu \mathrm{g} / \mathrm{rat}) 72 \mathrm{hr}$ before tests; Group 3, rats treated with oestradiol and progesterone received $5 \mathrm{mg}$ DL-amphetamine sulphate $/ \mathrm{kg}$ (Smith, Kline \& French Labs) $1 \mathrm{hr}$ before mating. Unmated control groups of rats 
injected with the drugs and hormones were simultaneously studied in each experiment. Mating tests were performed by the procedure of Meyerson (1964) and were conducted to obtain one full ejaculatory series (Adler et al., 1970) and induce a maximal rate of copulatory activity. Many of the drug-injected females were poorly receptive. Ejaculation was, therefore, taken as the reference point because, within a conventional time, a number of lordoses sufficient to elicit the neuroendocrine reflex would not have taken place. The females included in the experimental groups were only those which exhibited lordotic behaviour and presented a mucous plug on vaginal examination at the end of the period.

In order to analyse the effects of mating on the secretion of $\mathrm{LH}$, blood was obtained from each female through the jugular vein under light ether anaesthesia at 15, 30, 60 and 120 min after ejaculation had occurred. Other druginjected rats showing lordosis and not included in the tests of receptivity were also sampled to increase the number of animals in the Groups 2 and 3. Blood samples of unmated controls were taken at the same times. Plasma LH was measured by radioimmunoassay according to the recommendations of the NIAMDD, NIH, Bethesda, U.S.A., and expressed in ng NIH-LH-S1 preparation $/ \mathrm{ml}$. All the samples of several experiments were simultaneously assayed. Variance analysis and the Student's $t$ test were employed for statistical evaluation of the data.

Lordotic behaviour was maximal in Group-1 rats: receptivity to the males was $91.3 \%$ (21/23 rats were receptive). Treatment with PGPA elicited lordosis in $56.2 \%$ of the rats in Group $2(9 / 16)$ and amphetamine decreased receptivity to $58.8 \%$ of the rats in Group 3 (10/17). The lordosis quotients (lordosis/ mounts) were $0.85,0.72$ and 0.45 , respectively. The rats in Group 1 completed a full ejaculatory series in about $5 \mathrm{~min}$. After drug treatment, the series occupied 30 to $45 \mathrm{~min}$ in $11 / 19$ rats. In the rest of the rats $(8 / 19)$, the times of series were similar to those found in ovariectomized rats treated with oestrogen and progesterone.

Text-figure 1 shows that, in Group-1 rats mating resulted in a significant increase of plasma LH at $15 \mathrm{~min}(P<0.001)$ and at $30 \mathrm{~min}(P<0.01)$ after completion of one ejaculatory series, but was unable to increase plasma LH in Group-2 rats. A similar lack of response to mating was found in the Group-3 rats. When the duration of the ejaculatory series of each pair was checked against the LH levels, no statistically significant differences were found between the rats whose series lasted 30 to $45 \mathrm{~min}$ and the 'short series' rats. All results were therefore tabulated on the basis of the blood collection times as indicated above. Text-figure 1 shows that the mean levels of plasma LH in the controls for the amphetamine-treated rats were higher than those found in the controls for the Group-1 rats; variance analysis of these data indicated a significant difference between them $(P<0 \cdot 01)$.

Taleisnik et al. (1966), using a bioassay for LH, first demonstrated a rise of plasma LH levels after coitus in ovariectomized rats primed with oestrogen and progesterone, beginning about 10 min after the first intromission of the male. The results presented here indicate that this rise in LH levels is of about 30 min duration. Moss \& Cooper (1973) have reported that in normal prooestrous rats the elevation of LH levels after coitus lasts about $60 \mathrm{~min}$. 


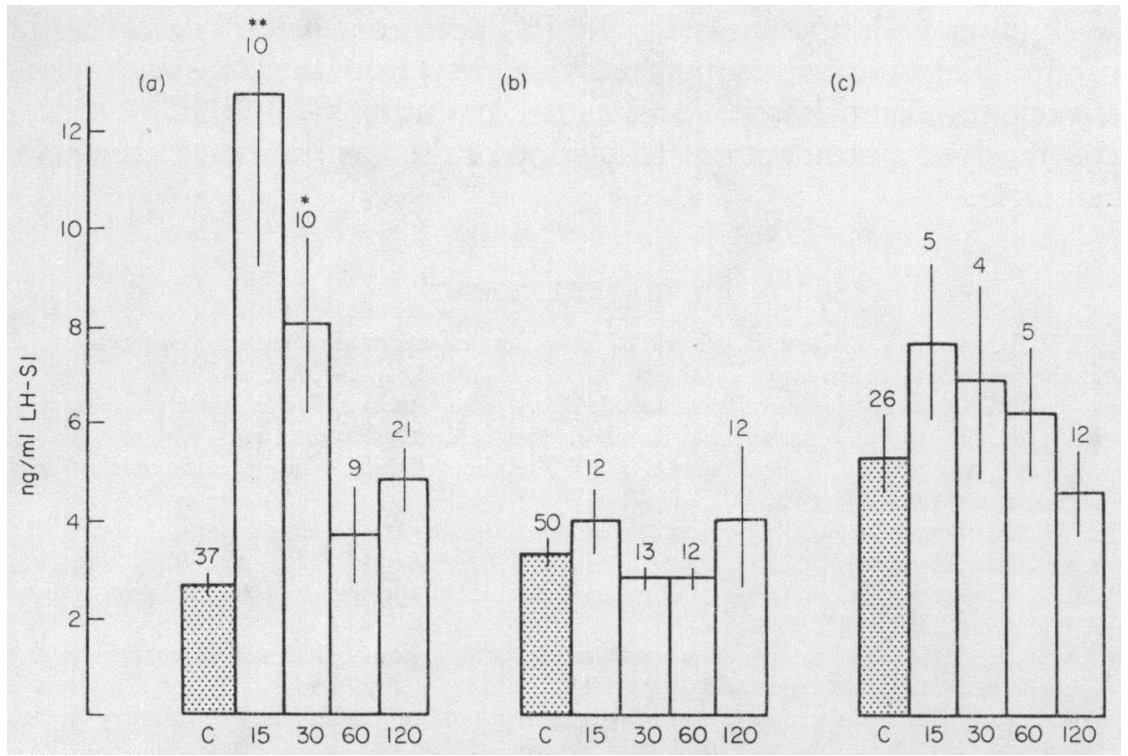

Text-Fig. 1. Plasma LH levels in ovariectomized mated rats at different times $\langle 15,30,60$ and $120 \mathrm{~min}$ ) after ejaculation. Vertical bars represent the S.E.M. Hatched columns represent control values $(\mathrm{C})$ and white columns post-coital values. The figures above the columns indicate the number of blood samples. (a) Group 1, ovariectomized rats treated with oestradiol benzoate and progesterone; (b) Group 2, rats primed with oestradiol benzoate and treated with $p$-chlorphenylalanine; (c) Group 3, rats primed with oestrogen and progesterone and injected with amphetamine sulphate. ${ }^{*} P<0.01$ compared with unmated controls; $* * P<0.001$.

In our experiments, treatment of oestrogen-primed ovariectomized rats with PCPA rendered $56 \%$ of them receptive to the males, though their lordosis quotient was a little lower than in rats primed with oestrogen and progesterone. Zemlan et al. (1973) reported that PGPA does not restore full oestrous behaviour, in that soliciting activity of the female is absent. Our results provide further evidence that PGPA-induced oestrous behaviour is incomplete, since no postcoital rise in plasma $\mathrm{LH}$ levels was detected in the rats displaying lordosis.

Our experiments with amphetamine confirm the oestrous-suppressing activity of this drug reported by Meyerson (1968). It diminished the incidence of oestrus to $58 \%$ in ovariectomized rats primed with oestrogen and progesterone and greatly reduced the lordosis quotient of the rats exhibiting lordotic behaviour. Furthermore, the normal post-coital rise in LH levels was not evident in these rats.

Moss \& Cooper (1973) and Deis (1973) have reported that among intact prooestrous rats, some exhibiting low lordosis quotients also had no post-coital rise in plasma LH levels. These observations and our present results suggests, therefore, that the post-coital rise in LH occurs with normal oestrous behaviour and that certain treatments which impair oestrous behaviour will abolish this rise of LH.

The present results also show that, in rats treated with amphetamine, LH levels are slightly but significantly elevated. The reason for this elevation is so far unexplained. 
The authors wish to thank Dr Fabio Sacerdote for collaboration in the manuscript. This study was supported by a grant from the Consejo Nacional de Investigaciones Cientificas y Tecnicas de Argentina (CONICET). One of us (S.T.B.) received a postdoctoral fellowship of the Instituto de Farmacologia y Bromatologia.

\section{REFERENCES}

Adler, N.T., Resko, J.A. \& Goy, R.W. (1970) The effect of copulatory behavior on hormonal change in the female rat prior to implantation. Physiol. Behav. 5, 1003-1007.

Axrlrod, J. (1970) Metabolic fate of the drugs. In The Mode of Action of Psychotomimetic Drugs, pp. 16-20. Ed. J. R. Smythies. Neurosciences Research Program, Massachusetts.

Davidson, J.M., SMith, E.R. \& Bowers, C.Y. (1973) Effects of mating on gonadotropin release in the female rat. Endocrinology 93, 1185-1192.

Deis, R.P. (1973) Secrecion de LH por excitacion sexual en la rata hembra virgen. Abstracts, 6th Congr. argent. Biol., Tucumán, p. 50.

KoE, B.K. \& WeISSMAN, A. (1966) p-Chlorphenylalanine: a specific depletor of brain serotonin. $\mathcal{F}$. Pharmac. exp. Ther. 154, 499-516.

Meyerson, B.J. (1964) Central nervous monoamines and hormone induced estrus behavior in the spayed rat. Acta physiol. scand. 63, Suppl. 241.

Meyerson, B.J. (1968) Amphetamine and 5-hydroxytryptamine inhibition of copulatory behaviour in the female rat. Annls Med. exp. Biol. Fenn. 46, 394-398.

Meyerson, B.J. \& Lewander, T. (1970) Serotonin synthesis inhibition and estrous behaviour in female rats. Life Sci. 9, 661-671.

Moss, R.L. \& Cooper, K.J. (1973) Temporal relationship of spontaneous and coitus-induced release of luteinizing hormone in the normal cyclic rat. Endocrinology 92, 1748-1753.

SpIEs, H.G. \& Niswender, G.D. (1971) Levels of prolactin, LH and FSH in the serum of intact and pelvic-neurectomized rats. Endocrinology 88, 937-943.

Taleisnik, S., Caligaris, L. \& Astrada, J.J. (1966) Effect of copulation on the release of pituitary gonadotropins in male and female rats. Endocrinology 79, 49-54.

Zemlan, F.P., Ward, I.L., Growley, W.R. \& Margules, D.L. (1973) Activation of lordotic responding in female rats by suppression of serotonergic activity. Science, N.Y. 179, 1010-1011. 